\title{
Brainstem Quadruple Aberrant Hyperphosphorylated Tau, Beta-Amyloid, Alpha-Synuclein and TDP-43 Pathology, Stress and Sleep Behavior Disorders
}

\author{
Lilian Calderón-Garcidueñas ${ }^{1,2, *}$, Ravi Philip Rajkumar ${ }^{3}{ }^{\circledR}$, Elijah W. Stommel ${ }^{4}$, Randy Kulesza ${ }^{5}$, \\ Yusra Mansour ${ }^{6}$, Adriana Rico-Villanueva ${ }^{2}$, Jorge Orlando Flores-Vázquez ${ }^{2}$, Rafael Brito-Aguilar ${ }^{2}$, \\ Silvia Ramírez-Sánchez ${ }^{2}$, Griselda García-Alonso ${ }^{2}$, Diana A. Chávez-Franco ${ }^{2}$, Samuel C. Luévano-Castro ${ }^{2}$, \\ Edgar García-Rojas ${ }^{2}$, Paula Revueltas-Ficachi ${ }^{2}$, Rodolfo Villarreal-Ríos ${ }^{7}$ and Partha S. Mukherjee ${ }^{8}$ (D)
}

check for

updates

Citation: Calderón-Garcidueñas, L.; Rajkumar, R.P.; Stommel, E.W.;

Kulesza, R.; Mansour, Y.;

Rico-Villanueva, A.; Flores-Vázquez, J.O.; Brito-Aguilar, R.;

Ramírez-Sánchez, S.; García-Alonso,

G.; et al. Brainstem Quadruple

Aberrant Hyperphosphorylated Tau,

Beta-Amyloid, Alpha-Synuclein and

TDP-43 Pathology, Stress and Sleep Behavior Disorders. Int. J. Environ. Res. Public Health 2021, 18, 6689.

https: / / doi.org/10.3390/

ijerph18136689

Academic Editor: Paul B. Tchounwou

Received: 31 May 2021

Accepted: 16 June 2021

Published: 22 June 2021

Publisher's Note: MDPI stays neutral with regard to jurisdictional claims in published maps and institutional affiliations.

Copyright: (c) 2021 by the authors. Licensee MDPI, Basel, Switzerland. This article is an open access article distributed under the terms and conditions of the Creative Commons Attribution (CC BY) license (https:// creativecommons.org/licenses/by/ $4.0 /)$.
1 Department of Biomedical \& Pharmaceutical Sciences, College of Health, The University of Montana, Missoula, MT 59812, USA

2 Universidad del Valle de México, Mexico City 14370, Mexico; adriana.rico@laureate.mx (A.R.-V.); jorge.flores@laureate.mx (J.O.F.-V.); rbritomu@hotmail.com (R.B.-A.); silvia.ramirezsa@uvmnet.edu (S.R.-S.); griselda.garcia@uvmnet.edu (G.G.-A.); alejeje01@gmail.com (D.A.C.-F.); y2j.luevano@hotmail.com (S.C.L.-C.); edgar.garcia@uvmnet.edu (E.G.-R.); paulirev97@gmail.com (P.R.-F.)

3 Department of Psychiatry, Jawaharlal Institute of Postgraduate Medical Education and Research, Pondicherry 605006, India; ravi.psych@gmail.com

4 Department of Neurology, Geisel School of Medicine at Dartmouth, Hanover, NH 03755, USA; Elijah.W.Stommel@hitchcock.org

5 Auditory Research Center, Lake Erie College of Osteopathic Medicine, Erie, PA 16509, USA; rjkulesza@gmail.com

6 Henry Ford Macomb, Department of Otolaryngology—Facial Plastic Surgery, Lake Erie College of Osteopathic Medicine, Erie, PA 16509, USA; Ymansour49902@med.LECOM.edu

7 Universidad Autónoma de Piedras Negras, Piedras Negras 26000, Mexico; rvillarreal45@hotmail.com

8 Interdisciplinary Statistical Research Unit, Indian Statistical Institute, Kolkata 700108, India; psmukherjee.statistics@gmail.com

* Correspondence: lilian.calderon-garciduenas@umontana.edu

Abstract: Quadruple aberrant hyperphosphorylated tau $(\mathrm{p}-\tau)$, amyloid- $\beta$ peptide, alpha-synuclein and TDP-43 brainstem and supratentorial pathology are documented in forensic $\leq 40 \mathrm{y}$ autopsies in Metropolitan Mexico City (MMC), and p- $\tau$ is the major aberrant protein. Post-traumatic stress disorder (PTSD) is associated with an elevated risk of subsequent dementia, and rapid eye movement sleep behavior disorder (RBD) is documented in PD, AD, Lewy body dementia and ALS. This study aimed to identify an association between PTSD and potential pRBD in Mexico. An anonymous online survey of 4502 urban college-educated adults, $29.3 \pm 10.3$ years; MMC, $\mathrm{n}=1865$; non-MMC, $\mathrm{n}=2637$, measured PTSD symptoms using the Impact of Event Scale-Revised (IES-R) and pRBD symptoms using the RBD Single-Question. Over 50\% of the participants had IES-R scores $\geq 33$ indicating probable PTSD. pRBD was identified in $22.6 \%$ of the participants across Mexico and $32.7 \%$ in MMC residents with PTSD. MMC subjects with PTSD had an OR 2.6218 [2.5348, 2.7117] of answering yes to the pRBD. PTSD and pRBD were more common in women. This study showed an association between PTSD and pRBD, strengthening the possibility of a connection with misfolded proteinopathies in young urbanites. We need to confirm the RBD diagnosis using an overnight polysomnogram. Mexican women are at high risk for stress and sleep disorders.

Keywords: Alzheimer; dementia; quadruple proteinopathies; nanoparticles; post-traumatic stress disorder; PTSD; possible REM sleep behavior disorder; pRBD; TDP-43 proteinopathies; Parkinson; Mexico 


\section{Introduction}

Recent evidence from around the world has identified a significant role for air pollution in the pathophysiology of dementia [1-5]. In our earlier research, neuropathological hallmarks of Alzheimer's disease (AD), Parkinson's disease (PD) and transactive response DNA-binding protein TDP-43 pathology in young megacity residents have been documented at post-mortem, even in toddlers [6-10]. These changes are associated with specific forms of air pollution, including exogenous magnetic Fe-rich nanoparticles resulting from fuel combustion and engineered Titanium (Ti) nanorods from e-waste $[6,9,11]$. In keeping with the quadruple abnormal protein pathology [6], Metropolitan Mexico City (MMC) children have lower CSF A $\beta 1-42$ and brain-derived neurotrophic factor (BDNF) concentrations versus controls ( $p=0.005$ and 0.02 , respectively) [12]. In an earlier study by our group, we applied the Montreal Cognitive Assessment (MoCA) to $517 \mathrm{MMC}$ residents, aged $21.60 \pm 5.88 \mathrm{y}$, with $13.7 \pm 1.3 \mathrm{y}$ of formal education [13]. The average MoCA score was $23.9 \pm 2.8$ (normal $26-30$ ), and $24.7 \%$ and $30.3 \%$ scored $\leq 24$ and $\leq 22$, corresponding to mild cognitive impairment $\mathrm{MCI} \leq 24$ and dementia scores $\mathrm{D} \leq 22$ [13]. Thus, urban Mexican populations may be at a heightened risk of long-term neurodegenerative sequel, including dementia associated with high exposure to neurotoxic air pollutants [14-18].

It is in this scenario that urban Mexican women are at high risk of traumatic events and the prevalence of post-traumatic stress disorder (PTSD) is high, with a significant lack of social and familial protection or support [19,20]. Rebeca Robles-Garcia and colleagues [19] analyzed PTSD in urban Mexican women, with a special focus on biopsychosocial risk factors, and discussed urbanization as a key factor due to the concentration of poverty, substance use, and crime. They argue and we agree-women are at a greater social and economic disadvantage resulting in them becoming victims of collective and domestic violence. Moreover, there is evidence at the international level that the female gender is associated with a 1.5 to 2-fold increase in the risk of post-traumatic stress disorder [21,22] as well as of specific sleep disorders [23], particularly REM sleep behavior disorder, which is the focus of the current study [24].

The stress problem is also documented in teenagers. As many as $80 \%$ of high school students in highly violent MMC areas have significant mental pathology associated with stress [25]. The impact of PTSD has recently been shown to extend far beyond its distressing psychological and social manifestations: there is a substantial body of evidence linking PTSD to a long-term risk of dementia, even after correction for potential sources of bias [26-31]. Olivé et al. [32] discuss the degeneration of the human basal forebrain as a putative link between persistent traumatic memory in PTSD and anterograde memory deficits in neurodegeneration, a plausible pathway in the setting of AD and PD pathology.

In this neurodegeneration setting, it is of interest that idiopathic REM sleep behavior disorder (iRBD), a parasomnia frequently associated with PD and dementia with Lewy Bodies [33], is more frequent in veterans with PTSD and traumatic brain injury (TBI + PTSD) [34], raising the possibility of a common denominator to iRBD and PTSD.

In light of the above information, this study examines two key aspects of psychological stress and sleep-namely PTSD and RBD in young middle-class Mexican adults residing in 101 Mexican cities. We hypothesized that, in this population, with documented quadruple abnormal protein brain aggregates-marking AD, $\mathrm{PD}$, and TDP-43 pathology—and clinically by cognitive deficits, there would be a strong association between $\mathrm{pRBD}$ and the symptoms of PTSD [6-10,13].

We selected two extensively validated instruments: the Spanish version of the Impact of Event Scale-Revised (IES-R), which includes 22 items measuring three clusters of PTSD risk: intrusion, avoidance and hyperarousal symptoms [35-41] and the REM Sleep Behavior Disorder Single-Question Screen (RBD1Q) to assess RBD [42].

\section{Methodology}

The current study was conducted in 101 urban areas across Mexico ranging in population from $\sim 21.8$ million people, i.e., MMC, to towns with $\leq 10,000$ residents. The research 
was conducted according to the Revised Helsinki Declaration of 2000 and the study was approved by the Universidad del Valle de México ethical and research committees. The data collection period was from 2 June to 3 July 2020, an anonymous online survey platform was used, and subjects were invited to participate. The invitation was aimed at college educated adults ( $\geq 18 \mathrm{y}$ ), either taking university classes online and/or working, followed by an explanation of the nature and purpose of the survey. Once the user consented to participate in the survey, they completed the following questions:

a. Demographic information, including city of residency, age, sex, formal education years, weight and height. Residents in Metropolitan Mexico City (MMC) and residents across 100 urban areas in the country (non-MMC) were included.

b. The Spanish version of the Impact of Event Scale-Revised (IES-R) was applied. For evaluation, the scores were divided into four categories: 0-23, no psychological impact or normal score; 24-32, mild psychological impact; 33-36, moderate psychological impact; $\geq 37$, severe psychological impact. A score of 33 or higher was selected as the most appropriate cut-off value for significant symptoms of probable PTSD in keeping with the literature [36-41]. The IES-R has well established validity and reliability [41] and in this work, the Cronbach's alpha was 0.832.

c. The REM Sleep Behavior Disorder Single-Question Screen (RBD1Q) assessing dream enactment with a single yes or no response. This question has a sensitivity of $94 \%$ and a specificity of $87 \%$ and consistently detects RBD in elderly populations [42-44].

\section{Statistical Analysis}

We calculated the descriptive statistics of all relevant variables in each group of MMC residents and non-residents, as well as in all participants combined. Next, we categorized the subjects in each residence-group according to their IES-R score. We also explored the summary statistics of numerous relevant variables within various groups and categories. We tested for equality of the subscale scores among MMC and non-MMC residents by performing independent-sample $t$-tests. We also tested for equality of the subscale scores within the category of IES-R $\leq 32, \geq 33$ and $\geq 37$, among the subjects having and not having PTSD, pRBD or having neither. For categorical variables (such as sex), we used Pearson's Chi-squared test. Finally, we calculated sample odds-ratios of the risk of PTSD and pRBD and calculated 99\% confidence intervals of the corresponding true odds-ratios. We performed the statistical analyses using Excel and the statistical software "R" (http:/ / www.r-project.org/, accessed on 1 May 2021).

\section{Results}

This is a cross sectional study of 4502 middle-class, college educated subjects with $61.48 \%$ women (Table 1 ). The mean total IES-R score was $33.30 \pm 15.28$ and $22.61 \%$ responded yes to the RBD1Q.

Table 1. Demographics in the 4502 participants: all subjects, Metropolitan Mexico City, and nonMetropolitan Mexico City subjects. Data in Mean (SD).

\begin{tabular}{cccc}
\hline Categories & $\begin{array}{c}\text { All Subjects } \\
\mathbf{n = 4 5 0 2}\end{array}$ & $\begin{array}{c}\text { MMC } \\
\mathbf{n = 1 8 6 5}\end{array}$ & $\begin{array}{c}\text { Non-MMC Subjects } \\
\mathbf{n}=\mathbf{2 6 3 7}\end{array}$ \\
\hline Age & $29.31(10.31)$ & $30.88(10.83)$ & $28.20(9.77)$ \\
\hline Sex $(\mathrm{M} / \mathrm{F})$ & $1734 / 2768$ & $731 / 1134$ & $1003 / 1634$ \\
\hline Years Education & $15.76(2.69)$ & $15.91(2.77)$ & $15.66(2.63)$ \\
\hline BMI & $25.56(5.10)$ & $25.51(5.01)$ & $25.59(5.17)$ \\
\hline IES-R total score & $33.30(15.28)$ & $33.73(15.46)$ & $32.99(15.15)$ \\
\hline \multirow{2}{*}{ RBD1Q } & $\mathrm{Y} / \mathrm{N}=1018 / 3484$ & $\mathrm{Y} / \mathrm{N}=455 / 14,010$ & $\mathrm{Y} / \mathrm{N}=563 / 2074$ \\
& $(22.61 \%)$ & $(24.40 \%)$ & $(21.35 \%)$ \\
\hline
\end{tabular}


The majority of individuals (50.44\%) scored above the cut-off value IES-R $\geq 33$ for PTSD and no differences were seen in the number of individuals in the severe category (IES$\mathrm{R} \geq 37$ ) between $\mathrm{MMC}$ versus non-MMC residents ( $p=0.14$, Chi-squared test) (Table 2 ).

Table 2. IES-R results in the four categories: normal, mild, moderate, and severe psychological stress. 4502 participants: all subjects, MMC and non-MMC subjects.

\begin{tabular}{cccc}
\hline $\begin{array}{c}\text { Categories } \\
\text { IES-R }\end{array}$ & $\begin{array}{c}\text { All Subjects } \\
\mathbf{n}=\mathbf{4 5 0 2}\end{array}$ & $\begin{array}{c}\text { MMC } \\
\mathbf{n = 1 8 6 5}\end{array}$ & $\begin{array}{c}\text { Non-MMC Subjects } \\
\mathbf{n}=\mathbf{2 6 3 7}\end{array}$ \\
\hline Normal (0-23) & $1215(26.99 \%)$ & 515 & 700 \\
& 1016 & 393 & $(26.54 \%)$ \\
\hline Mild (24-32) & $(22.57 \%)$ & $(21.07 \%)$ & 623 \\
& 467 & 185 & $(23.63 \%)$ \\
\hline Moderate (33-36) & $(10.37 \%)$ & $(9.92 \%)$ & 282 \\
\hline Severe $(\geq 37)$ & 1804 & 772 & $(10.69 \%)$ \\
\hline
\end{tabular}

An evaluation of the symptom subscales in the IES-R showed a significant difference in the responses to stress between $\mathrm{MMC}$ and non-MMC residents, with higher scores for intrusion $(p=0.0180)$ and hyperarousal $(p=0.03)$ in MMC, but non-significant statistical differences in avoidance $(p=0.67)$ (Table 3).

Table 3. IES-R subscale results in all, MMC, and non-MMC. Mean (SD).

\begin{tabular}{cccc}
\hline Subscale Score & All & MMC & Non-MMC \\
\hline Intrusion & $11.2 \pm 6.5$ & $11.5 \pm 6.6$ & $11.0 \pm 6.4$ \\
\hline Avoidance & $12.0 \pm 6.6$ & $12.0 \pm 6.5$ & $12.1 \pm 6.6$ \\
\hline Hyper-arousal & $9.9 \pm 5.6$ & $10.1 \pm 5.7$ & $9.8 \pm 5.5$ \\
\hline
\end{tabular}

Strikingly, $29.77 \%$ of all IES-R $\geq 33$ subjects answered yes to the pRBD question, with MMC residents reaching $32.71 \%$ (Table 4 ).

Table 4. Demographics for participants with IES-R scores of $\geq 33$. $n=2271$, all; $n=957$, MMC; $\mathrm{n}=1314$ non-MMC subjects. Data in Mean (SD).

\begin{tabular}{cccc}
\hline Variables IES-R $\geq \mathbf{3 3}$ & All $=\mathbf{2 2 7 1 / 4 5 0 2}$ & MMC $=\mathbf{9 5 7 / 1 8 6 5}$ & Non-MMC $=\mathbf{1 3 1 4 / 2 6 3 7}$ \\
\hline Age & $29.03(9.78)$ & $30.66(10.43)$ & $27.85(9.11)$ \\
\hline Sex $(\mathrm{M} / \mathrm{F})$ & $741 / 1530$ & $341 / 616$ & $400 / 914$ \\
\hline Years Education & $15.74(2.61)$ & $15.82(2.68)$ & $15.68(2.55)$ \\
\hline BMI & $25.59(5.08)$ & $25.56(5.05)$ & $25.61(5.11)$ \\
\hline IES-R total score & $45.46(9.92)$ & $45.90(10.01)$ & $45.13(9.85)$ \\
\hline \multirow{2}{*}{ RBD1Q } & $\mathrm{Y} / \mathrm{N}=676 / 1595$ & $\mathrm{Y} / \mathrm{N}=313 / 644$ & $\mathrm{Y} / \mathrm{N}=363 / 951$ \\
& $(29.8 \%)$ & $(32.7 \%)$ & $(27.6 \%)$ \\
\hline
\end{tabular}

On analysis of the subgroup with severe PTSD symptoms (IES-R score of $\geq 37$ ), those screening positive on the RBD1Q had significantly higher symptom scores on intrusion and hyperarousal $p<0.0001$ (Table 5). 
Table 5. Sub-scores in intrusion, avoidance and hyperarousal in participants who answered yes and no on the RBD1Q with total IES-R scores $\geq 37$.

\begin{tabular}{cccc}
\hline IES-R Total Score & Intrusion & Avoidance & Hyperarousal \\
\hline$\geq 37$, RBD1Q YES & $18.1(5.1)$ & $16.5(5.7)$ & $16.5(4.5)$ \\
\hline$\geq 37$, RBD1Q NO & $16.1(4.7)$ & $16.9(5.2)$ & $13.9(4.3)$ \\
\hline$p$-value & $<0.0001$ & 0.1773 & $<0.0001$ \\
\hline
\end{tabular}

For the entire sample, women had higher odds of developing symptoms of PTSD $(\mathrm{OR}=1.6562,99 \%$ confidence interval of true OR $[1.6400,1.6725])$ and pRBD (OR 1.1207 $[1.1051,1.1365])$ than men. Significantly, for MMC residents, the odds-ratio of PTSD versus non-PTSD subjects developing pRBD was 2.6218 [2.5348, 2.7117]. Residing in non-MMC regions was also associated with a higher risk of pRBD in women (OR 1.2408 [1.2094, 1.2729]) and an increased risk of screening positive for PTSD compared to men (OR1.9137 $[1.8812,1.9467])$. For the purpose of sample size justification and power calculations of two-sample $t$-tests and two-sample proportion tests, Tables 6 and 7 provide numerical details. For example, to detect an effect size of 0.10 with $80 \%$ power we need about 1570 subjects in each group in comparison. This justifies the sample size in our data.

Table 6. This table shows the minimum sample size required in each group to achieve the given power for detecting the respective effect size when the level of significance is $\alpha=0.05$ in all cases. This is for a two-sided two-sample $t$-test when the population standard deviation in both groups is roughly the same.

\begin{tabular}{llll}
\hline $\begin{array}{l}\text { Effect Size }= \\
\left(\boldsymbol{\mu}_{\mathbf{1}}-\boldsymbol{\mu}_{\mathbf{2}}\right) \boldsymbol{\sigma} \boldsymbol{\sigma}\end{array}$ & $\begin{array}{l}\text { Sample Size in Each } \\
\text { Group } \\
(\text { Power }=\mathbf{0 . 7 0 )}\end{array}$ & $\begin{array}{l}\text { Sample Size in Each } \\
\text { Group } \\
(\text { Power }=\mathbf{0 . 8 0})\end{array}$ & $\begin{array}{l}\text { Sample Size in Each } \\
\text { Group } \\
(\text { Power }=\mathbf{0 . 9 0 )}\end{array}$ \\
\hline 0.05 & 4938 & 6280 & 8406 \\
\hline 0.10 & 1235 & 1570 & 2102 \\
\hline 0.15 & 549 & 698 & 934 \\
\hline 0.20 & 309 & 393 & 526 \\
\hline 0.25 & 198 & 252 & 337 \\
\hline 0.30 & 138 & 175 & 234 \\
\hline
\end{tabular}

Table 7. This table shows the minimum sample size required in each group to achieve the given power for detecting the inequality in population proportions when the level of significance is $\alpha=0.05$ in all cases. This is for a two-sided two-sample proportion test.

\begin{tabular}{lllll}
\hline $\mathbf{p}_{\mathbf{1}}$ & $\mathbf{p}_{\mathbf{2}}$ & $\begin{array}{l}\text { Sample Size in } \\
\text { Each Group } \\
\text { (Power } \mathbf{0 . 7 0 )}\end{array}$ & $\begin{array}{l}\text { Sample Size in } \\
\text { Each Group } \\
\text { (Power } \mathbf{0 . 8 0 )}\end{array}$ & $\begin{array}{l}\text { Sample Size in } \\
\text { Each Group } \\
\text { (Power } \mathbf{0 . 9 0 )}\end{array}$ \\
\hline 0.10 & 0.15 & 540 & 686 & 918 \\
\hline 0.10 & 0.20 & 157 & 199 & 266 \\
\hline 0.10 & 0.25 & 79 & 100 & 133 \\
\hline 0.20 & 0.25 & 861 & 1094 & 1464 \\
\hline 0.20 & 0.30 & 231 & 294 & 392 \\
\hline 0.20 & 0.35 & 109 & 138 & 185 \\
\hline 0.30 & 0.35 & 1083 & 1377 & 1842 \\
\hline 0.30 & 0.40 & 281 & 356 & 477 \\
\hline 0.30 & 0.45 & 128 & 163 & 217 \\
\hline
\end{tabular}




\section{Discussion}

We open the discussion by emphasizing that this study explores a group of young, educated, middle-class and mostly female Mexican subjects, with significant published documentation of $\mathrm{AD}, \mathrm{PD}$ and TDP-43 pathology, using forensic autopsy cases and extensive published cognitive, olfaction, gait and equilibrium and brainstem auditory evoked potentials (BAEPs) studies in matching populations-a situation that makes this study very different from the average PTSD and sleep behavior disorder cases in the literature: the average case focuses on individuals who are male, significantly older, of low socioeconomic status, and possess extensive co-morbidities [6-10,12,13,26-34,42-47].

Moderate to severe psychological distress as measured by the IES-R was found to affect more than $50 \%$ of individuals and those with scores $\geq 33$ - suggestive in the literature of a probable diagnosis of PTSD [38,39] —showed a strong association with pRBD. Remarkably, for MMC residents, having moderate to severe psychological stress increased their odds of having pRBD by 2.6 -fold.

The association between stress and sleep related disorders and neurodegeneration is the core of this study. Song et al., explored a Swedish population of 44,839 individuals with stress-related disorders and their 78,482 unaffected siblings with a mean age of 47 years at the beginning of the 4.5 years ( 2.1 to 9.8 y) follow-up [26]. Compared with their control siblings, the stress diagnosed individuals had a higher risk of developing a vascular (HR 1.80; 95\% CI 1.40-2.31) neurodegenerative disease versus Alzheimer's (HR1.36; 95\% CI 1.12-1.67) [26]. Desmarais and colleagues [27] using keywords in their meta-analysis: PTSD and dementia found 25 articles reporting patients aged $67.4 \pm 7.1 \mathrm{y}$ with PTSD developing dementia $(n=14)$ and new onset or worsening of PTSD in patients $80.3 \pm 11.1$ y with dementia $(n=11)$. The authors discussed how PTSD could represent a prodromal stage of dementia. Interestingly, in their review work, Alzheimer's disease and vascular dementia were the most common neurodegenerative conditions, as were subjects with a history of early-life trauma. The authors concluded that repeated acute stress events and chronic stress conditions likely play a role in the bidirectional PTSD and dementia (i.e., neurodegeneration) relationships [27].

Of great interest to our study, are the clinicopathological correlations of 172 RBD cases by Boeve et al. [48]. The study group had $83 \%$ males, aged 20-93, and an average age at death of $75 \pm 9$ years. Their clinical diagnosis included Parkinsonism $(n=151)$, cognitive impairment $(n=147)$, and autonomic dysfunction $(n=42)$. At autopsy, Lewy body disease (LBD) $(\mathrm{n}=77)$, combined LBD and AD $(\mathrm{n}=59)$, multiple system atrophy (MSA) $(\mathrm{n}=19)$, $\operatorname{AD}(n=6)$ and progressive supranuclear palsy $(n=2)$ were diagnosed. In Boeve et al., RBD study, $94 \%$ of the subjects had documented synucleinopathies [48].

Clinical signs and cognition deficits are very useful to detect in early stages of neurodegeneration. McDade et al. [49] described RBD as associated with gait changes, while Shin et al. [50] made the association between RBD, cognitive decline and hyposmia.

Our results have to be discussed in light of the PTSD and RBD documented neuropathology, clinical associations in the literature and the various observations in our study that are worth highlighting. First, earlier research by our group has documented hallmarks of neurodegeneration in young $\leq 40$ year MMC residents, as evidenced by: (a) Alzheimer, Parkinson and TDP-43 neuropathology and high concentrations of highly reactive, oxidative and magnetic metal-rich nanoparticles (NPs) including exogenous engineered Ti-rich nanorods and non-metal nanoparticles $[6,7,10]$. (b) Olfactory bulb AD and PD pathology, along with olfaction deficits, are reported in MMC children and young adults and remarkably, Apolipoprotein E allele 4 carriers (APOE4) are 4.57 times more likely to die by suicide versus APOE 3 carriers, and have higher chances of exhibiting olfactory bulb neuronal alpha-synuclein aggregates and hyperphosphorylated tau neurites and tangles [8,47]. (c) Significant cognition deficits, gait, equilibrium and BAEPs abnormalities are present in seemingly MMC healthy children and young adults [13,45,46].

Second, the current study found a high prevalence (22.6\%) of pRBD in 4502 young people and this was strikingly higher $(32.7 \%)$ in MMC residents with an IES-R score $\geq 33$. 
These results are in sharp contrast to current literature, where most pRBD patients seeking medical care after injuries or at the request of partners, are male, with low education and over the age of $60 \mathrm{y}[43,51,52]$.

Third, for subjects with severe psychological stress (IES-R $\geq 37$ ), those screening positive for $\mathrm{pRBD}$ had significantly higher intrusion and hyperarousal responses $(<0.0001)$ indicating their higher risk with psychiatric morbidity [53].

The complex interplay between stressors, neurocognitive and neuropsychiatric manifestations, and documented evidence of quadruple misfolded protein neurodegenerative pathologies affecting Mexican urbanites from earliest childhood, supports a plausible relationship between neuro-psychiatric-cognitive features and evolving neurodegeneration. Ubiquitous, airborne and environmental, metal-rich magnetic nanoparticles, including e-waste metals, are a common denominator in the brains and hearts of MMC residents $[6,7,9,54,55]$. Strikingly, significant concentrations of ferrimagnetic NPs from cerebellum $>$ tectum/tegmentum/periaqueductal gray PAG $>$ substantia nigra acquire great importance when one considers the role of the brainstem and cerebellum in emotions, affective behavior, autonomic output, sleep-wake cycles, posture, gait, and major cholinergic innervations of the thalamic relay nuclei and the thalamic reticular nucleus [6,56-61].

Brainstem and supratentorial neuropathology in young MMC residents are extensive and could be playing a crucial role in the development of PTSD and pRBD (Figure 1) [26-30,48,49,62,63].

We want to draw attention to the fact that most of the brainstem, and specifically the substantia nigrae pathology in young MMC subjects [6], is in the form of hyperphosphorylated tau, in sharp contrast with dominant synucleinopathies in Boeve's work [48].

The main strengths of this study are the sample size of young, educated, middle-class, subjects across 101 Mexican cities, and the published data on neuropathology, CSF, cognition, brainstem auditory evoked potentials, olfaction and gait and equilibrium assessments in this target population. Our results strengthen the possibility of a robust connection between moderate to severe psychological stress and RBD and the association with neurodegeneration in young adults. Moreover, the key brainstem neuropathology marker in young Mexican urbanites is hyperphosphorylated tau.

We are aware of the limitations-including the screening for pRBD with the REM Sleep Behavior Disorder Single-Question instrument-requires that even assuming high sensitivity, a differential parasomnias diagnosis and other disorders, i.e., obstructive sleep apnea, has to be ruled out, and the gold standard diagnosis is an overnight video polysomnography (PSG) $[34,43,44]$. The need to implement a PSG in a representative sample is clear and urgent. The IES-R cut-off scores for a preliminary PTSD diagnosis are supported in the literature [38,39]. More than $50 \%$ of the subjects in this study had scores $\geq 33$ reflecting a probable diagnosis of PTSD, however, there is a need to confirm the PTSD diagnosis using a diagnostic interview for PTSD—the DSM-5 PCL (PTSD Checklist; PCL)—and to address the overlap and boundaries between ICD-11 definitions of complex post-traumatic stress disorder (C-PTSD) and personality disorder [64-67].

Finally, ethnic minorities are under-represented in PTSD and RBD studies and clinicians should be aware there are striking ethnic differences in rates of adult and childhood trauma exposure and PTSD among minorities [68]. 


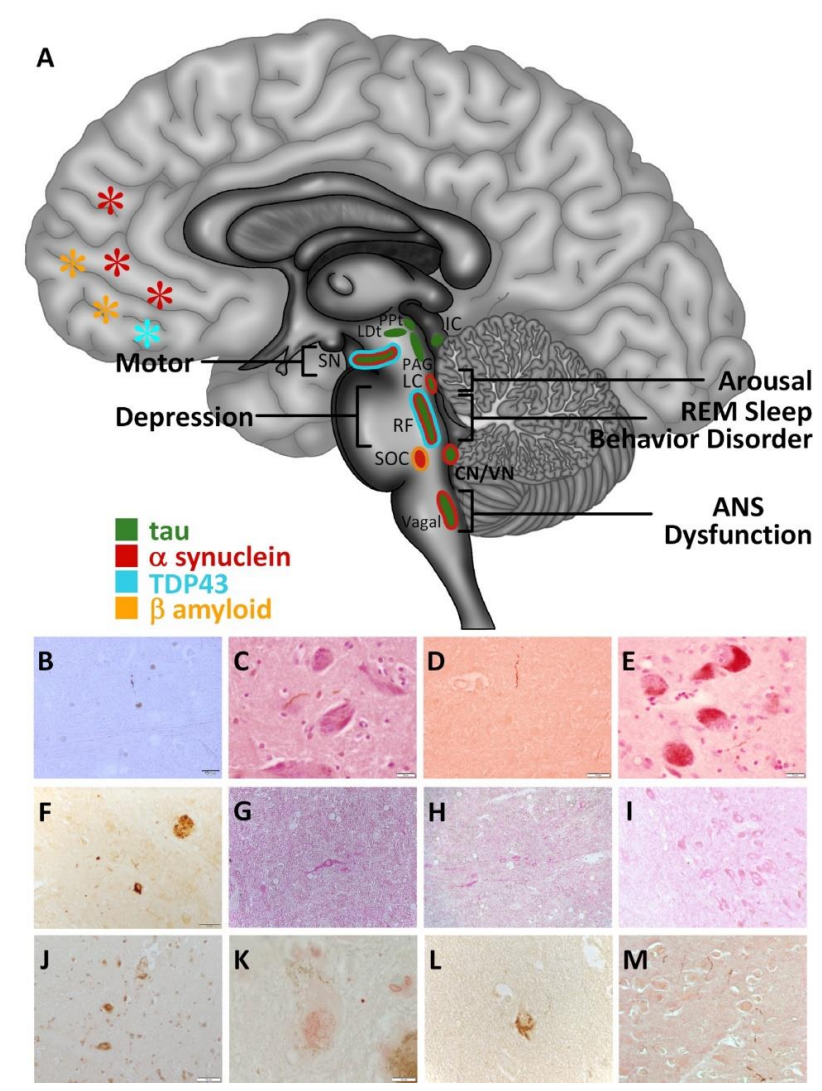

Figure 1. Distribution of misfolded proteins and neuropathological hallmarks in the brainstem and frontal cortex in Metropolitan Mexico City (MMC) individuals younger than 40 years [6-10,45,46]. The brainstem is an early target (motor, depression, arousal dysfunction and Autonomic Nervous System (ANS) dysfunction) [56-61] of misfolded proteins in Alzheimer, Parkinson and transactive response DNA-binding protein TDP-43 pathology in children and young adult residents in MMC [6]. (A) Brainstem pathology associated with RBD includes lesions in the pre-coeruleus, the sub-laterodorsal nucleus, magnocellular nucleus, the locus coeruleus, degeneration in pedunculopontine nucleus, and corticothalamic circuits affecting the pathways that regulate REM sleep in the brainstem. Autonomic nervous system dysfunction, motor alterations, depression, and arousal mechanisms are impaired when the brainstem is involved in patients with dementia with Lewy bodies, Parkinson's disease, multiple system atrophy and Alzheimer's disease. (B) Positive hyperphosphorylated tau neurite in the mesencephalic reticular formation in an $11 \mathrm{~m}$ old baby (PHF-tau 8, Innogenetics, Belgium). (C) Substantia nigra pars compacta in a 17 year old male with + tau neurites (PHF-tau 8, brown DAB, counterstained with hematoxylin). (D) Pedunculopontine nucleus positive tau neurite in a 12 y old boy (PHF-tau 8, brown DAB). (E) Locus coeruleus neurons with + tau neurites in a 37 year old female (PHF-tau 8, brown DAB). (F) Midbrain, substantia nigra + tau tangles in neurons + neurites and plaques in a 40 year old male (PHF-tau 8, brown DAB). (G) Three-year-old boy $+\alpha$-Syn neuron in the region of the medial lemniscus in the lower pons ( $\alpha$-Syn phosphorylated at Ser-129, LB 509, InVitrogen, Carlsbad, CA) (Red product). (H) Eleven y old female, lower medulla with numerous $\alpha$-Syn positive neurons and neurites in the reticular formation region (LB509, red product). (I) Thirteen-year-old girl, substantia nigra pars compacta neurons $+\alpha$-Syn (LB509, red product). (J) Fourteen-year-old male, pontine reticular formation several neurons with positive TDP-43 staining around mostly clear nuclei (TDP-43, mab 2G10, Roboscreen GmbH, Leipzig, Germany) (DAB, brown product). (K) Twenty-seven-year-old male, substantia nigra pars compacta neuron with neuromelanin degranulation and clearing of the nucleus (TDP-43, mab 2G10) (red product). (L) Frontal neuron tau positive in a 13-year-old female (PHF-tau 8, DAB brown product). (M) Eighteen-year-old male, frontal tau neurites cluster and neurons with $\mathrm{A} \beta$ perinuclear accumulation (PHF-tau 8, DAB brown product and beta amyloid 17-24 4G8 Covance, Emeryville, CA, USA, red product). 


\section{Conclusions}

We argue pRBD and PTSD in the third and fourth decades of life are not isolated diagnoses. Rather, they are likely to be part of a continuum of neurocognitive, neuropsychiatric, gait, equilibrium, and auditory manifestations starting in childhood and reflecting ongoing quadruple misfolded proteins. We can't ignore the neuropathology findings, $99.5 \%$ of 203 consecutive forensic autopsies in MMC could be staged for AD and the main marker was $p-\tau$ across all cases. It is concerning that the presence of pRBD in a large PD population-based study [69] is a clinical marker for faster cognitive decline.

We are aware of the overlap between neurodegenerative diseases. Most cases of dementia will have evidence of $\mathrm{AD}$, vascular changes, $\mathrm{PD}$, and TDP-43 pathology as shown by Karanth et al. [70]. Karanth and collaborators concluded that "quadruple misfolded proteins appear to be a common substrate for cognitive impairment and to be associated with an aggressive course of disease that typically ends with severe dementia" [70]. They also added that the overlap of aberrant proteins may complicate efforts to identify therapies to treat and prevent Alzheimer's disease. We agree with them.

Our previous work focused on the relationship between air pollution and early neuropathological changes suggestive of dementia, which has been confirmed in systematic reviews of the literature [71]. In the current study, we have chosen to focus on the link between post-traumatic stress disorder and REM sleep behavior disorder, because the emerging evidence of a significant increase in the risk of subsequent neurodegeneration in patients with PTSD [72] and that disturbed sleep may be a significant mediator of this association [73]. There is also evidence that REM sleep behavior disorder, which has been consistently associated with neurodegenerative disorders, is more frequent in individuals with PTSD [34,74]. Potential cellular mechanisms underlying this association, such as oxidative stress and inflammation, are being elucidated [75], and these mechanisms overlap substantially with those that link environmental pollution and neurodegeneration [76]. Therefore, we wish to highlight the potential of a synergistic interaction between these two factors in increasing the subsequent risk of neurodegenerative disorders, particularly dementia. Though not directly examined in this study, this hypothesis is supported by an extensive body of literature.

We strongly support that we need to understand the factors that contribute to the neurodegenerative overlapping pathogenic cascade, and studying young populations at risk for neurodegeneration will enable prevention, earlier detection, and the discovery of targeted strategies to stop the development and progression of fatal neurodegenerative diseases affecting our populations. It is a matter of significant concern that women in this cohort were particularly affected by PTSD and pRBD. It is critical that these women are identified, diagnosed and treated, chiefly because of their higher psychiatric morbidity risk [53] and the fact that urban Mexican women are at very high risk for collective and domestic violence [19].

Understanding the interplay between neurodegeneration, sleep disorders, and PTSD in the first four decades of life ought to be a research priority for one key reason: identifying individuals at the earliest disease stages will shed light on molecular pathways that could be targeted for interventions aimed to avoid or ameliorate neurodegeneration, decrease stress, and ultimately to develop early disease-modifying treatments for AD, PD and TDP-43 diseases.

Author Contributions: Conception and design of the study, L.C.-G., P.S.M., R.P.R., A.R.-V. and J.O.F.-V.; acquisition and analysis of data, A.R.-V., J.O.F.-V., R.B.-A., E.G.-R., P.R.-F., G.G.-A., S.R.-S., R.V.-R., D.A.C.-F. and S.C.L.-C.; drafting of the text, writing, critical analysis, and preparing the figures-L.C.-G., P.S.M., R.P.R., E.W.S., R.K., Y.M.; statistical analysis, P.S.M. All authors have read and agreed to the published version of the manuscript.

Funding: This research received no specific grant from any funding agency in the public, commercial, or not-for-profit sectors. 
Institutional Review Board Statement: The study was conducted according to the guidelines of the Declaration of Helsinki, and approved by the Universidad del Valle de Mexico Institutional Review Board.

Informed Consent Statement: Informed consent was obtained from all subjects involved in this anonymous online study.

Data Availability Statement: All data are available in the paper.

Conflicts of Interest: The authors declare no conflict of interest.

Ethical Approval: All subjects gave their informed consent for inclusion before they participated in the study. The study was conducted in accordance with the Declaration of Helsinki, and the protocol was approved by the Ethics Committee of Universidad del Valle de Mexico. Adult subjects consented to their anonymous participation.

\section{References}

1. Jung, C.R.; Lin, Y.T.; Hwang, B. Ozone, Particulate Matter, and Newly Diagnosed Alzheimer's Disease: A Population-Based Cohort Study in Taiwan. J. Alzheimer's Dis. 2015, 44, 573-584. [CrossRef] [PubMed]

2. Chen, H.; Kwong, J.C.; Copes, R.; Tu, K.; Villeneuve, P.J.; van Donkelaar, A.; Hystad, P.; Martin, R.V.; Murray, B.J.; Jessiman, B.; et al. Living near major roads and the incidence of dementia, Parkinson's disease, and multiple sclerosis: A population-based cohort study. Lancet 2017, 389, 718-726. [CrossRef]

3. Lee, P.C.; Liu, L.L.; Sun, Y.; Chen, Y.A.; Liu, C.C.; Li, C.Y.; Yu, H.L.; Ritz, B. Traffic-related air pollution increased the risk of Parkinson's disease in Taiwan: A nationwide study. Environ. Int. 2016, 96, 75-81. [CrossRef]

4. Hu, C.Y.; Fang, Y.; Li, F.L.; Dong, B.; Hua, X.G.; Jiang, W.; Zhang, H.; Lyu, Y.; Zhang, X.J. Association between ambient air pollution and Parkinson's disease: Systematic review and meta-analysis. Environ. Res. 2019, 168, 448-459. [CrossRef]

5. Mortamais, M.; Gutierrez, L.A.; de Hoogh, K.; Chen, J.; Vienneau, D.; Carrière, I.; Letellier, N.; Helmer, C.; Gabelle, A.; Mura, T.; et al. Long-term exposure to ambient air pollution and risk of dementia: Results of the prospective Three-City Study. Environ. Int. 2021, 148, 106376. [CrossRef]

6. Calderón-Garcidueñas, L.; González-Maciel, A.; Reynoso-Robles, R.; Hammond, J.; Kulesza, R.; Lachmann, I. Quadruple abnormal protein aggregates in brainstem pathology and exogenous metal-rich magnetic nanoparticles. The substantia nigrae is a very early target in young urbanites and the gastrointestinal tract likely a key brainstem portal. Environ. Res. 2020, 191, 110139. [CrossRef]

7. Calderón-Garcidueñas, L.; Gónzalez-Maciel, A.; Reynoso-Robles, R.; Delgado-Chávez, R.; Mukherjee, P.S.; Kulesza, R.J.; TorresJardon, R.; Avila-Ramirez, J.; Villarreal-Rios, R. Hallmarks of Alzheimer disease are evolving relentlessly in Metropolitan Mexico City infants, children and young adults. APOE4 carriers have higher suicide risk and higher odds of reaching NFT stage V at $\leq 40$ years of age. Environ. Res. 2018, 164, 475-487. [CrossRef]

8. Calderón-Garcidueñas, L.; González-Maciel, A.; Reynoso-Robles, R.; Kulesza, R.J.; Mukherjee, P.S.; Torres-Jardón, R.; Ronkko, T.; Doty, R.L. Alzheimer's disease and alpha-synuclein pathology in the olfactory bulbs of infants, children, teens and adults $\leq 40$ years in Metropolitan Mexico City. APOE4 carriers at higher risk of suicide accelerate their olfactory bulb pathology. Environ. Res. 2018, 166, 348-362. [CrossRef] [PubMed]

9. Calderón-Garcidueñas, L.; Robles, R.R.; González-Maciel, A. Combustion and friction-derived nanoparticles and industrialsourced nanoparticles: The culprit of Alzheimer and Parkinson's diseases. Environ. Res. 2019, 176, 108574. [CrossRef] [PubMed]

10. Calderón-Garcidueñas, L.; Torres-Jardón, R.; Kulesza, R.J.; Mansour, Y.; González-González, L.O.; Gónzalez-Maciel, A.; ReynosoRobles, R.; Mukherjee, P.S. Alzheimer disease starts in childhood in polluted Metropolitan Mexico City. A major health crisis in progress. Environ. Res. 2020, 183, 109137. [CrossRef]

11. Ceballos, D.; Zhou, M.; Herrick, R. Metals and Particulates Exposure from a Mobile E-Waste Shredding Truck: A Pilot Study. Ann. Work Expo. Health 2020, 64, 890-896. [CrossRef]

12. Calderón-Garcidueñas, L.; Avila-Ramírez, J.; Calderón-Garcidueñas, A.; Gonzalez-Heredia, T.; Acuna-Ayala, H.; Chao, C.; Thompson, C.; Ruiz-Ramos, R.; Cortes-Gonzalez, V.; Martinez-Martinez, L.; et al. Cerebrospinal Fluid Biomarkers in Highly Ex-posed PM2.5 Urbanites: The Risk of Alzheimer's and Parkinson's Diseases in Young Mexico City Residents. J. Alzheimer's. Dis. 2016, 54, 597-613. [CrossRef]

13. Calderón-Garcidueñas, L.; Mukherjee, P.S.; Kulesza, R.J.; Torres-Jardón, R.; Hernández-Luna, J.; Ávila-Cervantes, R.; MaciasEscobedo, E.; Gonzalez-Gonzalez, O.; Gonzalez-Maciel, A.; Research Universidad del Valle de México UVM Group; et al. Mild Cognitive Impairment and Dementia Involving Multiple Cognitive Do-mains in Mexican Urbanites. J. Alzheimer's Dis. 2019, 68, 1113-1123.

14. Molina, L.T.; Velasco, E.; Retama, A.; Zavala, M. Experience from Integrated Air Quality Management in the Mexico City Metropolitan Area and Singapore. Atmosphere 2019, 10, 512. [CrossRef]

15. Zavala, M.; Molina, L.T.; Yacovitch, T.I.; Fortner, E.C.; Roscioli, J.R.; Floerchinger, C.; Herndon, S.C.; Kolb, C.E.; Knighton, W.B.; Paramo, V.H.; et al. Emission factors of black carbon and co-pollutants from diesel vehicles in Mexico City. Atmos. Chem. Phys. Discuss. 2017, 17, 15293-15305. [CrossRef] 
16. Villalobos-Pietrini, R.; Amador-Muñoz, O.; Valle-Hernández, B.; Gomez-Arroyo, S.; Waliszewski, S. Organic Compound in Airborne Particles and their Genotoxic Effects in Mexico City. Air Quality Monitoring Assessment and Management. 2011. Available online: https:/ / www.intechopen.com/books/air-quality-monitoring-assessment-and-management/organic-compound-inairborne-particles-and-their-genottoxic-effects-in-mexico-city (accessed on 10 May 2021).

17. Caudillo, L.; Salcedo, D.; Peralta, O.; Castro, T.; Ospina, H.A. Nanoparticle size distributions in Mexico city. Atmos. Pollut. Res. 2020, 11, 78-84. [CrossRef]

18. Mugica-Alvarez, V.; Figueroa-Lara, J.; Romero-Romo, M.; Sepúlveda-Sánchez, J.; López-Moreno, T. Concentrations and properties of airborne particles in the Mexico City subway system. Atmos. Environ. 2012, 49, 284-293. [CrossRef]

19. Robles-García, R.; Fresán, A.; Yoldi, M. Posttraumatic stress disorder in urban women. Curr. Opin. Psychiatry 2020, 33, 245-249. [CrossRef]

20. Cortés-Álvarez, N.Y.; Piñeiro-Lamas, R.; Vuelvas-Olmos, C.R. Psychological Effects and Associated Factors of COVID19 in a Mexican Sample. In Disaster Medical Public Health Preparedness; 2020; pp. 1-12. Available online: https: //www.cambridge.org/core/journals/disaster-medicine-and-public-health-preparedness/article/psychological-effectsand-associated-factors-of-covid19-in-a-mexican-sample/7F6A1DB36F91BA6957BF1D0743F683B4 (accessed on 7 May 2021).

21. Dai, W.; Chen, L.; Lai, Z.; Li, Y.; Wang, J.; Liu, A. The incidence of post-traumatic stress disorder among survivors after earthquakes:a systematic review and meta-analysis. BMC Psychiatry 2016, 16, 188. [CrossRef] [PubMed]

22. Grenier, S.; Payette, M.C.; Gunther, B.; Askari, S.; Desjardins, F.F.; Raymond, B.; Berbiche, D. Association of age and gender with anxiety disorders in older adults: A systematic review and meta-analysis. Int. J. Geriatr. Psychiatry 2019, 34, 397-407. [CrossRef] [PubMed]

23. Suh, S.; Cho, N.; Zhang, J. Sex Differences in Insomnia: From Epidemiology and Etiology to Intervention. Curr. Psychiatry Rep. 2018, 20, 69. [CrossRef]

24. Zhou, J.; Zhang, J.; Li, Y.; Du, L.; Li, Z.; Lei, F.; Wing, Y.K.; Kushida, C.A.; Zhou, D.; Tang, X. Gender differences in REM sleep behavior disorder: A clinical and polysomnographic study in China. Sleep Med. 2015, 16, 414-418. [CrossRef]

25. Mendoza-Mojica, S.A.; Márquez-Mendoza, O.; Veytia-López, M.; Ramos-Lira, L.E.; Orozco-Zavala, R. Eventos potencialmente traumáticos y sintomatología postraumática en estudiantes de preparatoria [Potentially traumatic events and post-traumatic symptomatology in high school students]. Salud Publica Mex. 2017, 59, 665-674. [CrossRef] [PubMed]

26. Song, H.; Sieurin, J.; Wirdefeldt, K.; Pedersen, N.L.; Almqvist, C.; Larsson, H.; Valdimarsdóttir, U.A.; Fang, F. Association of Stress-Related Disorders with Subsequent Neurodegenerative Diseases. JAMA Neurol. 2021, 77, 700-709. [CrossRef]

27. Desmarais, P.; Weidman, D.; Wassef, A.; Bruneau, M.A.; Friedland, J.; Bajsarowicz, P.; Thibodeau, M.P.; Herrmann, N.; Nguyen, Q.D. The Interplay between Post-traumatic Stress Disorder and Dementia: A Systematic Review. Am. J. Geriatr. Psychiatry 2020, 28, 48-60. [CrossRef]

28. Neylan, T.C. Post-traumatic Stress Disorder and Neurodegeneration. Am. J. Geriatr. Psychiatry 2020, 28, 61-63. [CrossRef]

29. Günak, M.M.; Billings, J.; Carratu, E.; Marchant, N.L.; Favarato, G.; Orgeta, V. Post-traumatic stress disorder as a risk factor for dementia: Systematic review and meta-analysis. Br. J. Psychiatry 2020, 217, 600-608. [CrossRef] [PubMed]

30. Nilaweera, D.; Freak-Poli, R.; Ritchie, K.; Chaudieu, I.; Ancelin, M.L.; Ryan, J. The long-term consequences of trauma and posttraumatic stress disorder symptoms on later life cognitive function and dementia risk. Psychiatry Res. 2020, $294,113506$. [CrossRef]

31. Saadi, A.; Cruz-Gonzalez, M.; Hwang, A.; Cohen, L.; Alegria, M. Associations between Trauma, Sleep, and Cognitive Impairment Among Latino and Asian Older Adults. J. Am. Geriatr. Soc. 2021, 69, 1019-1026. [CrossRef] [PubMed]

32. Olivé, I.; Makris, N.; Densmore, M.; McKinnon, M.C.; Lanius, R.A. Altered basal forebrain BOLD signal variability at rest in posttraumatic stress disorder: A potential candidate vulnerability mechanism for neurodegeneration in PTSD. Hum. Brain Mapp. 2021. online ahead of print. [CrossRef]

33. Galbiati, A.; Verga, L.; Giora, E.; Zucconi, M.; Ferini-Strambi, L. The risk of neurodegeneration in REM sleep behavior disorder: A systematic review and meta-analysis of longitudinal studies. Sleep Med. Rev. 2019, 43, 37-46. [CrossRef]

34. Elliot, J.E.; Opel, R.A.; Pleshakov, D.; Rachakonda, T.; Chau, A.Q.; Weymann, K.B.; Lim, M.M. Posttraumatic stress disorder increases the odds of REM sleep behavior disorder and other parasomnias in Veterans with and without comorbid traumatic brain injury. Sleep 2020, 43, zsz237. [CrossRef] [PubMed]

35. Horowitz, M.J.; Wilner, N.; Alvarez, W. Impact of Event Scale: A Measure of Subjective Stress. Psychosom. Med. 1979, 41, 209-218. [CrossRef] [PubMed]

36. Weiss, D.S.; Marmar, C.R. The Impact of Event Scale-Revised. In Assessing Psychological Trauma and PTSD; Wilson, J., Keane, T.M., Eds.; Guilford: New York, NY, USA, 1996; pp. 399-411.

37. Baguena, M.J.; Villarroya, E.; Beleña, A.; Amelia, D.; Roldán, C.; Reig, R. Psychometric properties of the Spanish version of the Impact of Event Scale-Revised (IES-R). Análisis Modif. Conducta 2001, 27, 581-604.

38. Tiemensma, J.; DePaoli, S.; Winter, S.D.; Felt, J.M.; Rus, H.M.; Arroyo, A.C. The performance of the IES-R for Latinos and non-Latinos: Assessing measurement invariance. PLoS ONE 2018, 13, e0195229. [CrossRef]

39. Creamer, M.; Bell, R.; Failla, S. Psychometric properties of the Impact of Event Scale-Revised. Behav. Res. Ther. 2003, 41, 1489-1496. [CrossRef]

40. Hyland, P.; Shevlin, M.; Fyvie, C.; Karatzias, T.J. Posttraumatic Stress Disorder and Complex Posttraumatic Stress Disorder inDSM-5andICD-11: Clinical and Behavioral Correlates. J. Trauma. Stress 2018, 31, 174-180. [CrossRef] 
41. Weiss, D.S. The impact of event scale: Revised. In Cross Cultural Assessment of Psychological Trauma and PTSD; Wilson, J.P., Tang, C.S., Eds.; Springer: Berlin/Heidelberg, Germany, 2007; pp. 219-238.

42. Postuma, R.B.; Arnulf, I.; Hogl, B.; Iranzo, A.; Miyamoto, T.; Dauvilliers, Y.; Oertel, W.H.; Ju, Y.-E.; Puligheddu, M.; Jennum, P.; et al. A single-question screen for rapid eye movement sleep behavior disorder: A multicenter validation study. Mov. Disord. 2012, 27, 913-916. [CrossRef] [PubMed]

43. Postuma, R.B.; Iranzo, A.; Hu, M.; Högl, B.; Boeve, B.F.; Manni, R.; Oertel, W.H.; Arnulf, I.; Ferini-Strambi, L.; Puligheddu, M.; et al. Risk and predictors of dementia and parkinsonism in idiopathic REM sleep behaviour disorder: A multicentre study. Brain 2019, 142, 744-759. [CrossRef]

44. Yao, C.; Fereshtehnejad, S.M.; Keezer, M.R.; Wolfson, C.; Pelletier, A.; Postuma, R.B. Risk factors for possible REM sleep behavior disorder: A CLSA population-based cohort study. Neurology 2018, 92, e475-e485. [CrossRef]

45. Calderón-Garcidueñas, L.; Kulesza, R.J.; Mansour, Y.; Aiello-Mora, M.; Mukherjee, P.S.; González-González, L.O. Increased Gain in the Auditory Pathway, Alzheimer's Disease Continuum, and Air Pollution: Peripheral and Central Auditory System Dys-function Evolves Across Pediatric and Adult Urbanites. J. Alzheimer's Dis. 2019, 70, 1275-1286. [CrossRef]

46. Calderón-Garcidueñas, L.; Torres-Solorio, A.K.; Kulesza, R.J.; Torres-Jardón, R.; González-González, L.O.; García-Arreola, B.; Chávez-Franco, D.A.; Luévano-Castro, S.C.; Hernández-Castillo, A.; Carlos-Hernández, E.; et al. Gait and balance disturbances are common in young urbanites and associated with cognitive impairment. Air pollution and the historical development of Alzheimer's disease in the young. Environ. Res. 2020, 191, 110087. [CrossRef]

47. Calderón-Garcidueñas, L.; Franco-Lira, M.; Henríquez-Roldán, C.; Osnaya, N.; González-Maciel, A.; Reynoso-Robles, R.; Villarreal-Calderon, R.; Herritt, L.; Brooks, D.; Keefe, S.; et al. Urban air pollution: Influences on olfactory function and pathology in exposed children and young adults. Exp. Toxicol. Pathol. 2010, 62, 91-102. [CrossRef] [PubMed]

48. Boeve, B.F.; Silber, M.H.; Ferman, T.J.; Lin, S.C.; Benarroch, E.E.; Schmeichel, A.; Ahlskog, J.; Caselli, R.; Jacobson, S.; Sabbagh, M.; et al. Clinicopathologic correlations in 172 cases of rapid eye movement sleep behavior disorder with or without a coexisting neurologic disorder. Sleep Med. 2013, 14, 754-762. [CrossRef] [PubMed]

49. McDade, E.M.; Boot, B.P.; Christianson, T.J.; Pankratz, V.S.; Boeve, B.F.; Ferman, T.J.; Bieniek, K.; Hollman, J.H.; Roberts, R.O.; Mielke, M.M.; et al. Subtle gait changes in patients with REM sleep behavior disorder. Mov. Disord. 2013, 28, 1847-1853. [CrossRef]

50. Shin, C.; Lee, J.Y.; Kim, J.K.; Nam, H.; Yoon, E.J.; Shin, S.A.; Kim, H.-J.; Jeon, B. Cognitive decline in association with hyposmia in idiopathic rapid eye movement sleep behavior disorder: A prospective 2-year follow-up study. Eur. J. Neurol. 2019, 26, 1417-1420. [CrossRef]

51. Roguski, A.; Rayment, D.; Whone, A.L.; Jones, M.W.; Rolinski, M. A Neurologist's Guide to REM Sleep Behavior Disorder. Front. Neurol. 2020, 11, 610. [CrossRef] [PubMed]

52. St Louis, E.K.; Boeve, B.F. REM Sleep Behavior Disorder: Diagnosis, Clinical Implications, and Future Directions. Mayo Clin. Proc. 2017, 92, 1723-1736. [CrossRef]

53. Parrado-González, A.; León-Jariego, J.C. COVID-19: Factores asociados al malestar emocional y morbilidad psíquica en pobla-ción española [Covid-19: Factors associated with emotional distress and psychological morbidity in Spain]. Rev. Esp. Salud Publica 2020, 94, e202006058.

54. Maher, B.A.; Ahmed, I.A.M.; Karloukovski, V.; MacLaren, D.A.; Foulds, P.G.; Allsop, D.; Mann, D.M.A.; Torres-Jardón, R.; Calderon-Garciduenas, L. Magnetite pollution nanoparticles in the human brain. Proc. Natl. Acad. Sci. USA 2016, 113, 10797-10801. [CrossRef]

55. Calderón-Garcidueñas, L.; González-Maciel, A.; Mukherjee, P.S.; Robles, R.R.; Perez-Guille, B.; Gayosso-Chávez, C.; Torres-Jardón, R.; Cross, J.V.; Ahmed, I.A.M.; Karloukovski, V.V.; et al. Combustion- and friction-derived magnetic air pollution nanoparticles in human hearts. Environ. Res. 2019, 176, 108567. [CrossRef] [PubMed]

56. Garcia-Rill, E.; Saper, C.; Rye, D.B.; Kofler, M.; Nonnekes, J.; Lozano, A.; Valls-Solé, J.; Hallett, M. Focus on the pedunculopontine nucleus. Consensus review from the May 2018 brainstem society meeting in Washington, DC, USA. Clin. Neurophysiol. 2019, 130, 925-940. [CrossRef]

57. Venkatraman, A.; Edlow, B.L.; Immordino-Yang, M.H. The Brainstem in Emotion: A Review. Front. Neuroanat. 2017, 11, 15. [CrossRef] [PubMed]

58. Adamaszek, M.; D’Agata, F.; Ferrucci, R.; Habas, C.; Keulen, S.; Kirkby, K.C.; Leggio, M.; Mariën, P.; Molinari, M.; Moulton, E.; et al. Consensus Paper: Cerebellum and Emotion. Cerebellum 2017, 16, 552-576. [CrossRef] [PubMed]

59. Zelena, D.; Menant, O.; Andersson, F.; Chaillou, E. Periaqueductal gray and emotions: The complexity of the problem and the light at the end of the tunnel, the magnetic resonance imaging. Endocr. Regul. 2018, 52, 222-238. [CrossRef]

60. Pierce, J.E.; Péron, J. The basal ganglia and the cerebellum in human emotion. Soc. Cogn. Affect. Neurosci. 2020, 15, 599-613. [CrossRef]

61. Zhang, Y.; Larcher, K.M.; Misic, B.; Dagher, A. Anatomical and functional organization of the human substantia nigra and its connections. eLife 2017, 6, e26653. [CrossRef]

62. Miyamoto, T.; Miyamoto, M.; Numahata, K.; Onoue, H.; Akaiwa, Y.; Sairenchi, T. Reduced dopamine transporter binding predicts early transition to Lewy body disease in Japanese patients with idiopathic rapid eye movement sleep behavior disorder. J. Neurol. Sci. 2020, 414, 116821. [CrossRef] [PubMed] 
63. Zhang, F.; Niu, L.; Liu, X.; Liu, Y.; Li, S.; Yu, H.; Wet, L. Rapid Eye Movement Sleep Behavior Disorder and Neurodegenerative Diseases: An Update. Aging Dis. 2020, 11, 315-326. [CrossRef]

64. American Psychiatric Association. Diagnostic and Statistical Manual of Mental Disorders: (DSM-5®); American Psychiatric Publishing: Arlington, VA, USA, 2013.

65. Davidson, J.R.; Book, S.W.; Colket, J.T.; Tupler, L.A.; Roth, S.; David, D.; Hertzberg, M.; Mellman, T.; Beckham, J.C.; Smith, R.D.; et al. Assessment of a new self-rating scale for post-traumatic stress disorder. Psychol. Med. 1997, 27, 153-160. [CrossRef]

66. Felding, S.U.; Mikkelsen, L.B.; Bach, B. Complex PTSD and personality disorder in ICD-11: When to assign one or two diagnoses? Australas. Psychiatry 2021. [CrossRef] [PubMed]

67. LeardMann, C.A.; McMaster, H.S.; Warner, S.; Esquivel, A.P.; Porter, B.; Powell, T.M.; Tu, X.M.; Lee, W.W.; Rull, R.P.; Hoge, C.W.; et al. Comparison of Posttraumatic Stress Disorder Checklist Instruments From Diagnostic and Statistical Manual of Mental Disorders, Fourth Edition vs Fifth Edition in a Large Cohort of US Military Service Members and Veterans. JAMA Netw. Open 2021, 4, e218072. [CrossRef] [PubMed]

68. Gluck, R.L.; Hartzell, G.E.; Dixon, H.D.; Michopoulos, V.; Powers, A.; Stevens, J.S.; Fani, N.; Carter, S.; Schwartz, A.C.; Jovanovic, T.; et al. Trauma exposure and stress-related disorders in a large, urban, predominantly African-American, female sample. Arch. Women's Ment. Health 2021. online ahead of print. [CrossRef] [PubMed]

69. Folle, A.D.; Paul, K.; Bronstein, J.M.; Keener, A.M.; Ritz, B. Clinical progression in Parkinson's disease with features of REM sleep behavior disorder: A population-based longitudinal study. Park. Relat. Disord. 2019, 62, 105-111. [CrossRef]

70. Karanth, S.; Nelson, P.T.; Katsumata, Y.; Kryscio, R.J.; Schmitt, F.A.; Fardo, D.W.; Cykowski, M.D.; Jicha, G.A.; Van Eldik, L.J.; Abner, E.L. Prevalence and Clinical Phenotype of Quadruple Misfolded Proteins in Older Adults. JAMA Neurol. 2020, 77, 1299-1307. [CrossRef] [PubMed]

71. Peters, R.; Ee, N.; Peters, J.; Booth, A.; Mudway, I.; Anstey, K.J. Air Pollution and Dementia: A Systematic Review. J. Alzheimer's Dis. 2019, 70, S145-S163. [CrossRef]

72. Rafferty, L.A.; Cawkill, P.E.; Stevelink, S.A.M.; Greenberg, K.; Greenberg, N. Dementia, post-traumatic stress disorder and major depressive disorder: A review of the mental health risk factors for dementia in the military veteran population. Psychol. Med. 2018, 48, 1400-1409. [CrossRef]

73. Delic, V.; Ratliff, W.A.; Citron, B.A. Sleep Deprivation, a Link between Post-Traumatic Stress Disorder and Alzheimer's Disease. J. Alzheimer's Dis. 2021, 79, 1443-1449. [CrossRef] [PubMed]

74. Lee, E.; Kim, K.; So, H.S.; Choi, J.H.; Yoon, I.Y.; Choi, H. REM Sleep Behavior Disorder among Veterans with and without Post-Traumatic Stress Disorder. Psychiatry Investig. 2020, 17, 987-995. [CrossRef]

75. Miller, M.W.; Lin, A.P.; Wolf, E.; Miller, D.R. Oxidative Stress, Inflammation, and Neuroprogression in Chronic PTSD. Harv. Rev. Psychiatry 2018, 26, 57-69. [CrossRef] [PubMed]

76. Hahad, O.; Lelieveld, J.; Birklein, F.; Lieb, K.; Daiber, A.; Münzel, T. Ambient Air Pollution Increases the Risk of Cerebrovascular and Neuropsychiatric Disorders through Induction of Inflammation and Oxidative Stress. Int. J. Mol. Sci. 2020, $21,4306$. [CrossRef] [PubMed] 